\title{
Pharmaceutical Care in Ontario
}

\author{
Jacqueline Dzionek \\ La Colombe Pharmacy, Ottawa Ontario, Canada \\ (iD) https://orcid.org/0000-0002-7052-4403 \\ Corresponding author: jacquelinedzionek@hotmail.com
}

DOI: https://doi.org/10.20883/medical.e458

Keywords: pharmacist, expanded scope of practice, services, medication management, prescribing, injections
Published: 2020-12-29

How to cite: Dzionek J. Pharmaceutical Care in Ontario. JMS [Internet]. 2020 Dec 29;89(4):e458. doi:10.20883/medical.e458

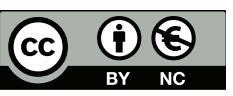

(c) 2020 by the author(s). This is an open access article distributed under the terms and conditions of the Creative Commons Attribution (CC BY-NC) licencse. Published by Poznan University of Medical Sciences

\begin{abstract}
Pharmaceutical care is an integral part of global healthcare. Indeed, pharmacists are recognised as a primary point of care, providing many services to optimise the patient's healthcare. The article provides insight on how expanding the scope of pharmacists' practice can facilitate collaboration between healthcare providers, relieve the workload of the physicians, also providing patients with optimal healthcare service globally. This article focuses specifically on the expanded scope of pharmacists in Ontario, Canada and the services that pharmacists can provide in the pharmacy for all patients.
\end{abstract}

Over the years, pharmaceutical care as pharmacists has grown worldwide. Indeed, the industry for pharmacists has expanded, whether working in pharmaceutical companies, academia, hospital pharmacies, or community pharmacies [1]. In Canada, there are over 45,000 licensed pharmacists, with over 11,000 pharmacies providing healthcare to all Canadians [2]. Traditionally, pharmacists would dispense medications but over the years, the scope of practice has expanded and pharmacists can deliver more innovative services to benefit public health. These services not only provide the most appropriate medication management for the patient but allow pharmacists to collaborate with their healthcare providers to optimise their healthcare [3]. Depending on the province or territory the pharmacist is in, the scope of practice/authority may differ slightly, but the main services such as medication reviews, chronic disease management, immunisation services and wellness checks are available country-wide [4,5]. This article will focus on the province of Ontario and the services pharmacists can provide to improve healthcare for all patients. The types of services are listed in Figure 1.

\section{Prescriptive authority for smok- ing/tobacco cessation}

Pharmacists are available to enrol patients who are covered under the provincial health insurance programme (OHIP) into the Smoke Free Ontario Strategy programme [6], providing support to patients who are willing to quit smoking, as well as access to appropriate medications to help in cessation [6]. This facilitates the appropriate therapy since pharmacists are familiar with the medications as well as patient adherence, which is a key element in the smoking cessation programme. 


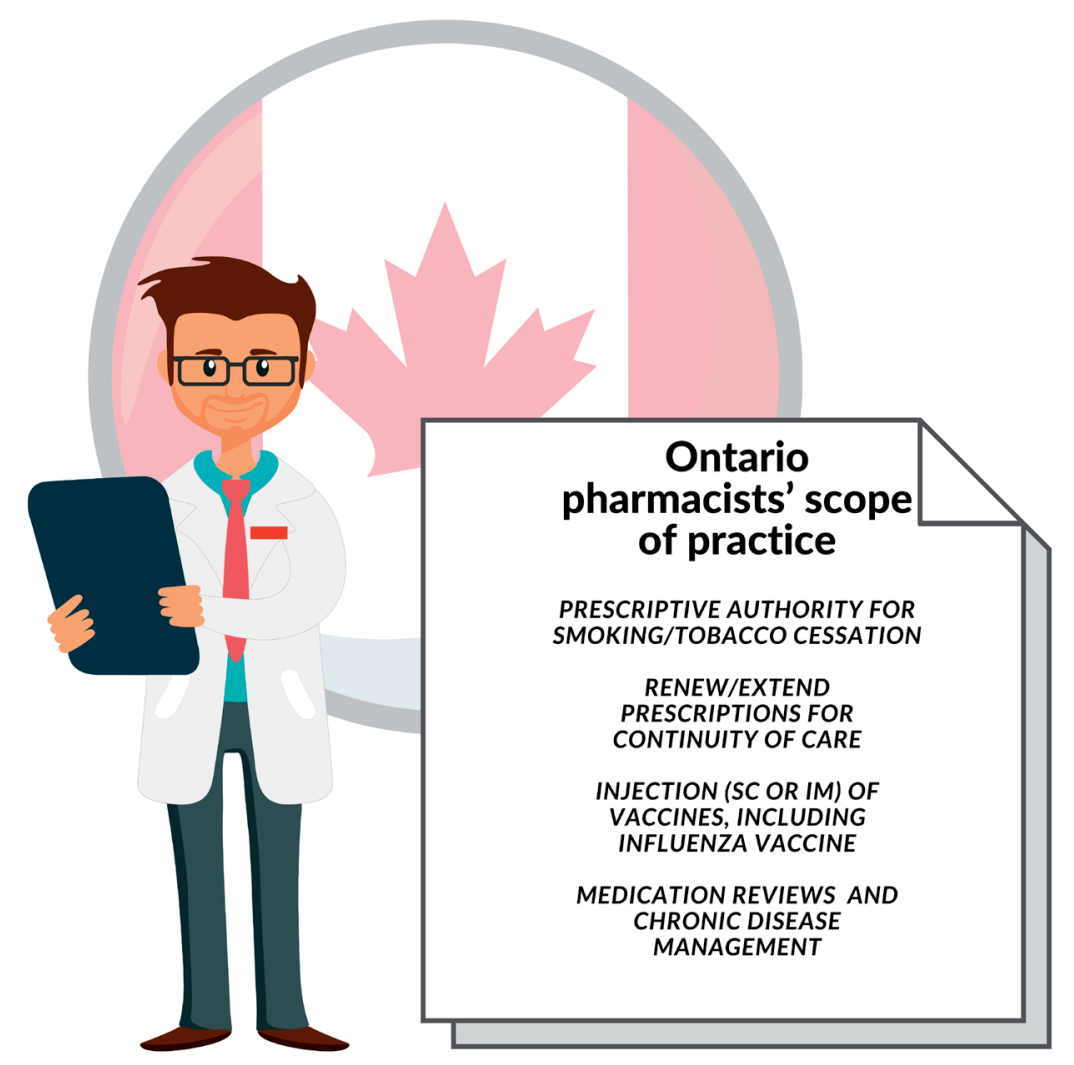

Figure 1. Types of services provided by pharmacists in Ontario, Canada $[4,5]$

\section{Renew/extend prescrip- tions for continuity of care}

Pharmacists can renew and extend prescriptions under certain rules and regulations [4,5]. When adapting a prescription, the pharmacist has the right to alter the dose, the form of medication and route of administration to benefit the patient's needs or circumstances [7]. The adaptation does not include changing the medication or active ingredient. When renewing a prescription, the pharmacist may renew for the total quantity that was originally prescribed by the prescriber, including refills, or a six-month supply of that prescription [7]. However, to do so, the guidelines state that the pharmacist must be in possession and/or have access to the original prescription to be renewed or adapted. The pharmacist must also assess the patient to determine if the therapy is safe and outweighs the benefits over risk, seek consent from the patient or their authorised agent and provide proper documentation and notification to the prescriber (within a reasonable time after the mentioned above) to ensure continuity of care [7]. It is important to note, pharmacists do not have the right to renew or adapt any controlled substance whether it be narcotics, controlled and targeted substances or any medication that is monitored under the Narcotic Safety and Awareness Act [7].

\section{Injection (SC or IM) of vaccines, including influenza vaccine}

For a pharmacist to administer an injection, they are required to have completed training approved by the OCP (Ontario College of Pharmacists) and register their training and maintain an active certification in CPR and First Aid [5,8,9]. Pharmacists can administer injections for the following circumstances $[8,9]$ :

, The patient is 5 years of age or older and consent has been obtained from the patient (or their authorised agent)

, The injections are administered in an environment that is safe and clean following all appropriate infection control procedures

, The patient has been prescribed an injection that they can self-administer but they (or their 
authorised agent) prefer to have the injection dispensed and administered by the pharmacist for education and demonstration of how to administer the injection

, Patients prescribed Schedule I vaccine specified in regulations

, Patients requiring a Schedule II vaccine specified in regulations

, Administering the influenza vaccine under the Universal Influenza Immunisation Programme

2 Substances that are not listed in any of the schedules may be administered in a medical directive context

, List of vaccinations that can be administered by pharmacists can be found in Figure 2 .

After receiving an administered injection, the pharmacist must have all proper documentation as well as informed their PCP (primary care provider) of the administered injection [8,9]. Pharmacists can monetarily charge administering injections for patients who meet the criteria for publicly funded vaccines but they must inform the patient that they can receive the vaccine administered by their PCP at no cost to the patient [9].

\section{Medication reviews and chron- ic disease management}

Medication reviews are an opportunity for pharmacists to meet and educate their patients on the medications they are taking to optimise their healthcare. In 2007, the MedsCheck programme was initiated for patients in Ontario taking a minimum of three medications for a chronic condition [11]. Over the years, the programme has expanded and is now available to patients who are residents of long-term care homes, patients with diabetes and home-bound patients who are unable to visit the pharmacy [11]. The MedsCheck programme helps pharmacists to understand their patients and identify problems as well as help resolve medication issues for the most beneficial usage of the medication. During this review, pharmacists will consult the patient one-on-one and answer any questions that they have about their medications whether prescribed and/or over the counter, help patients understand their medications and what they do, inform and/or identify adverse effects the patient can expect but most

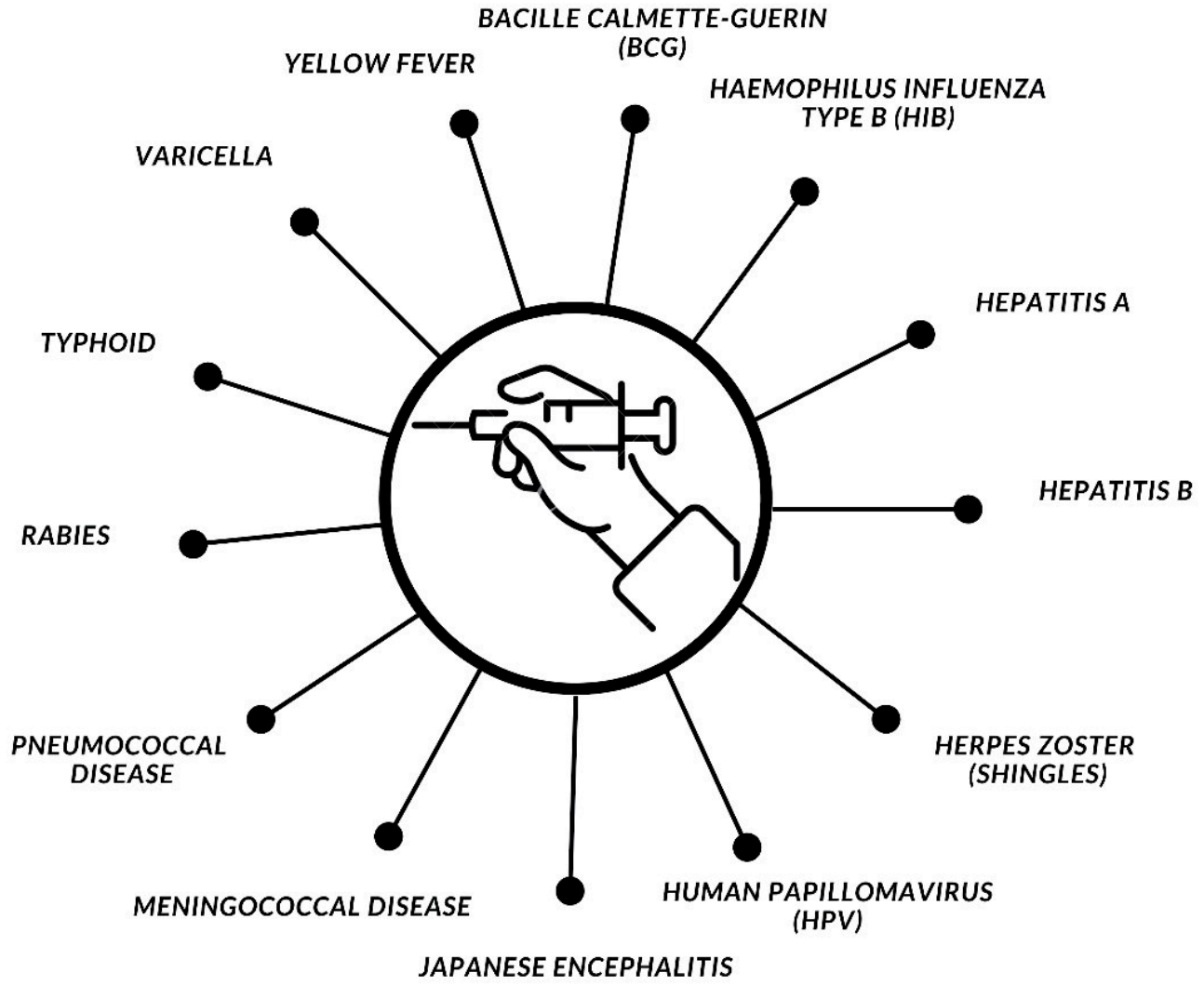

Figure 2. Types of vaccinations that pharmacists can administer in Ontario [10] 
importantly, the pharmacist now has a complete and accurate medication list for the patient, which can be shared with their PCP to support collaboration to optimise the patient's healthcare [11].

\section{Discussion}

The scope of practice for Ontario pharmacists is continuing to grow, with pharmacists becoming experts on medication management and providing advice and suggestions to the health care team. With over 15,000 licensed pharmacists, the increased scope of practice of renewing medication, being able to provide injections, and safer medication management provides easier access to healthcare, as well as helping to ease the amount of work for the patient's PCP, thereby providing patients with the most optimal healthcare. This is not only seen and proven in Ontario but in other provinces in Canada and countries who have expanded the scope of practice for pharmacists. In provinces such as Alberta, Saskatchewan, Manitoba and New Brunswick, pharmacists can initiate a prescription for chronic diseases under certain restrictions [12]. In Quebec, pharmacists cannot initiate a new prescription but are allowed to adjust doses to meet a therapeutic target as well as prescribe a new dose to meet that target [12]. In America, pharmacists are also allowed to administer injections [13]. It has been shown that due to the pharmacists' ability to provide medication management therapy, they could create an "inferred diagnosis" from medication reviews and identify the need for a vaccine [14]. It also facilitates the administration of the vaccine because most PCPs do not stock the vaccine in their offices and the pharmacist can dispense and administer the vaccine [14]. This helps the PCP because it reduces the workload and it is not necessary for the patient to return to the clinic. Around the world, many countries such as the United Kingdom, Ireland, Portugal and Australia have expanded the scope to allow pharmacists to administer injections [15,16]. Pharmacists in England, Scotland and Wales can prescribe, supply and administer medicines and medical devices using their knowledge of medications to ensure their prescribing services are provided safely and effectively [17]. The United Kingdom has also intro- duced the 'New Medicine Service' that provides patients with extra support from pharmacists when starting a new medical treatment for certain chronic conditions [18,19]. The New Medicine Services provides a series of three appointments with a scheme for patients to follow while taking their new medication for the first time, all while being closely monitored by the pharmacist to ensure proper adherence and understanding of the treatment [20]. Nevertheless, there are countries, such as Poland, who have not expanded the scope of practice for pharmacists that would greatly benefit from such an expansion. With an expansion to their practice, like in Ontario, there is potential for pharmacists in Poland to provide better medication management, open the doors for communication between patients and their PCPs and improve pharmaceutical care [21].

\section{Conclusion}

With an expanded scope of practice, pharmacists are positioned to play an integral role in the healthcare system. The expanded services that pharmacists can provide may increase accessibility to a healthcare professional for patients, shorten wait times at a physician's clinic as well as reduce the physician's workload by administering injections or providing extended prescriptions. For the continued and future expansion of services to optimise global healthcare, it is important to educate patients, as well as physicians, about the services pharmacists can provide.

\section{Acknowledgements}

I would like to sincerely thank Mikołaj Seostianin MD 6th year student at PUMS for all his hard work in designing the graphics.

\section{Conflict of interest statement}

The authors declare no conflict of interest.

\section{Funding sources}

There are no sources of funding to declare.

\section{References}

1. Get to know the different roles pharmacists play. https://www.opatoday.com/tips-and-commonquestions/tip-sheets/PharmacistRoles. Accessed 2020 August 8.

2. National Statistics . https://napra.ca/national-statistics. Accessed 2020 August 8. 
3. Pharmacists in Canada. https://www.pharmacists. $\mathrm{ca} /$ pharmacy-in-canada/pharmacists-in-canada. Accessed 2020 August 8.

4. Pharmacists' expanded scope of practice . https:// www.pharmacists.ca/pharmacy-in-canada/scopeof-practice-canada. Accessed 2020 August 8.

5. Pharmacists' Scope of Practice in Canadian Jurisdictions. https://napra.ca/sites/default/files/2020-01/ SCOPE $\% 200 F \% 20 P R A C T I C E \% 20-\% 20$ January $\% 20$ 2020_0.pdf. Accessed 2020 August 11.

6. Pharmacy smoking cessation program. http://www. health.gov.on.ca/en/pro/programs/drugs/smoking. Accessed 2020 August 11.

7. Initiating, adapting and renewing prescriptions. https://www.ocpinfo.com/regulations-standards/ practice-policies-guidelines/adapting-renewingprescriptions. Accessed 2020 August 11.

8. Administering a substance by injection or inhalation. https://www.ocpinfo.com/regulations-standards/ practice-policies-guidelines/inhalation. Accessed 2020 August 11.

9. Pharmacists now authorized to administer additional vaccines. Pharmacy Connection. Winter 2017;1829. https://www.ocpinfo.com/wp-content/uploads/ documents/OCP_PharmacyConnection_Winter2017_ AdditionalVaccines.pdf

10. PharmacyAct, 1991 OntarioRegulation202/94.https:// www.ontario.ca/laws/regulation/940202\#BK37. Accessed 2020 August 11.

11. MedCheck Program. https://www.opatoday.com/ professional/resources/for-pharmacists/programs/ medscheck. Accessed 2020 August 11.

12. Bhatia S, Simpson SH, Bungard T. Provincial Comparison of Pharmacist Prescribing in Canada Using Alberta's Model as the Reference Point. The Canadian Journal of Hospital Pharmacy. 2017 Oct 30;70(5). https://doi.org/10.4212/cjhp.v70i5.1696

13. Immunization Center. https://www.pharmacist.com/ immunization-center. Accessed 2020 September 18.
14. Bach A, Goad J. The role of community pharmacy-based vaccination in the USA: current practice and future directions. Integrated Pharmacy Research and Practice. 2015 Jul;:67. https://doi.org/10.2147/iprp.s63822

15. Houle SKD, Carter CA, Tsuyuki RT, Grindrod KA. Remunerated patient care services and injections by pharmacists: An international update. Canadian Pharmacists Journal / Revue des Pharmaciens du Canada. 2019 Jan 24;152(2):92-108. https://doi. org/10.1177/1715163518811065

16. Houle SKD, Grindrod KA, Chatterley T, Tsuyuki RT. Publicly funded remuneration for the administration of injections by pharmacists. Canadian Pharmacists Journal / Revue des Pharmaciens du Canada. 2013 Sep 26;146(6):353-364. https://doi. org/10.1177/1715163513506369

17. General Pharmaceutical Council - In practice: Guidance for pharmacist prescribers. https://www.pharmacyregulation.org/sites/default/files/document/ in-practice-guidance-for-pharmacist-prescribersfebruary-2020.pdf. Accessed 2020 September 28.

18. What to expect from your pharmacy team. https:// www.nhs.uk/using-the-nhs/nhs-services/pharmacies/new-medicine-service-nms. Accessed 2020 September 28.

19. Latif A, Waring J, Watmough D, Barber N, Chuter A, Davies J, Salema N, Boyd MJ, Elliott RA. Examination of England's New Medicine Service (NMS) of complex health care interventions in community pharmacy. Research in Social and Administrative Pharmacy. 2016 Nov;12(6):966-989. https://doi.org/10.1016/j. sapharm.2015.12.007

20. New Medicine Service (NMS). https://www.nhs.uk/ using-the-nhs/nhs-services/pharmacies/new-medicine-service-nms. Accessed 2020 September 28.

21. Neumann-Podczaska A. Optymalizacja leczenia farmakologicznego osób starszych. Poznań: Wydawnictwo Naukowe Uniwersytetu Medycznego im. Karola Marcinkowskiego w Poznaniu; 2019. 